\title{
Evolutionary Optimization of Electronic Circuitry Cooling Using Nanofluid
}

\author{
Manu Mital \\ Mechanical and Nuclear Engineering, Virginia Commonwealth University, Richmond, VA 23284, USA \\ Correspondence should be addressed to Manu Mital, mmital@vcu.edu
}

Received 9 October 2012; Revised 23 November 2012; Accepted 2 December 2012

Academic Editor: Huijun Gao

Copyright () 2012 Manu Mital. This is an open access article distributed under the Creative Commons Attribution License, which permits unrestricted use, distribution, and reproduction in any medium, provided the original work is properly cited.

Liquid cooling electronics using microchannels integrated in the chips is an attractive alternative to bulky aluminum heat sinks. Cooling can be further enhanced using nanofluids. The goals of this study are to evaluate heat transfer in a nanofluid heat sink with developing laminar flow forced convection, taking into account the pumping power penalty. The proposed model uses semiempirical correlations to calculate effective nanofluid thermophysical properties, which are then incorporated into heat transfer and friction factor correlations in literature for single-phase flows. The model predicts the thermal resistance and pumping power as a function of four design variables that include the channel diameter, velocity, number of channels, and nanoparticle fraction. The parameters are optimized with minimum thermal resistance as the objective function and fixed specified value of pumping power as the constraint. For a given value of pumping power, the benefit of nanoparticle addition is evaluated by independently optimizing the heat sink, first with nanofluid and then with water. Comparing the minimized thermal resistances revealed only a small benefit since nanoparticle addition increases the pumping power that can alternately be diverted towards an increased velocity in a pure water heat sink. The benefit further diminishes with increase in available pumping power.

\section{Background and Introduction}

Power and semiconductor electronic systems find widespread application in residential, commercial, military, and space environments. In everyday life, these systems are commonly used in televisions, automobiles, telephones, computers, and so forth. Due to their widespread use, electronics chips need to operate reliably under a wide variety of environmental conditions. One of the key factors that affects reliability is thermal management. The difference between the input and the output energy in an electronic system is converted to heat, which must be removed efficiently to prevent overheating and chip failures. Efficient thermal management will be a key enabling technology for the future growth of electronics. This work is motivated by the need to address this issue at the component (chip) level. The methodology presented here can be used for optimal design of on-chip microchannel heat sinks with nanofluid flow. The current study takes into consideration that the flow is not fully developed due to the short length of these microchannels (the literature review reveals that often the optimization is done using fully developed heat transfer and pumping power correlations). Furthermore, the current study takes into consideration the increase in pumping power due to nanoparticle addition (whereas several studies in the literature perform this optimization by only considering the benefit of particle addition at a given flow rate and not the pumping power penalty). Finally, the current study evaluates the benefit of nanoparticle addition by independently optimizing the nanofluid and base fluid heat sinks at a specified pumping power.

1.1. Microchannel Cooling for Thermal Management. Microchannels are compact cooling elements that can provide increased heat dissipation rates and reduced temperature gradients across electronic components. Tuckerman and Pease [1] were the first to propose the use of microchannel cooling and showed that heat transfer coefficients on the order of $10^{5} \mathrm{~W} / \mathrm{m}^{2} \cdot \mathrm{K}$ can be achieved, corresponding to cooling capabilities of up to $790 \mathrm{~W} / \mathrm{cm}^{2}$ using water as the coolant. Unlike traditional heat sinks that need a large 
surface area to increase heat dissipation rates, microchannels use small diameter channels to increase the heat transfer coefficient by forcing the coolant in close contact with the channel walls. The heat transfer coefficient (and therefore the heat dissipation) increases as the flow channel diameter is decreased. Based on channel diameter, Mehendale et al. [2] classified the range from 1 to $100 \mu \mathrm{m}$ as microchannels, $100 \mu \mathrm{m}$ to $1 \mathrm{~mm}$ as mesochannels, $1-6 \mathrm{~mm}$ as compact passages, and larger than $6 \mathrm{~mm}$ as traditional passages. Kandlikar and Grande [3] provide a review of the evolution of microchannel technology, both in terms of their performance and the processes used to fabricate them.

1.2. Microchannel Cooling Using Nanofluids. The removal of heat using microchannel heat sinks can be enhanced using nanofluids (liquid solutions with dispersed nanometer-sized particles) as reported by numerous studies in the literature, a summary of which is presented in recent key review articles [5-8]. This enhancement has been attributed to changes in effective thermophysical properties (increase in thermal conductivity and decrease in viscosity), although the exact mechanisms are currently not well understood and are an area of active research. Several researchers have investigated the reason for enhanced heat transfer in nanofluids. Das et al. [9] have noted that the properties of a nanofluid (especially thermal conductivity and viscosity) cannot be estimated as weighted average of the fluid and solid nanoparticle components using simple mixture rules. This is because the properties of a nanofluid depend on several factors (related to nanofluid microstructure) such as the component properties, component volume fractions, particle size, particle geometry, particle distribution, matrixparticle interfacial effects, and particle motion. The particle motion (believed to have a significant contribution to enhanced heat transfer observed in nanofluids) is governed by superposition of several effects (thermophoresis, Saffman lift force, Brownian motion, Soret and Dufour effects, etc.), some of which are not yet fully understood since they only become significant at very small length scales. Wang et al. [10] reported that a combination of several factors such as particle motion, surface action, and electrokinetic effects caused the enhanced heat transfer in nanofluids. This study was the first to suggest that particle size may be an important contributing factor. Xuan and Li [11] suggested increased surface area of particles per unit volume, collision between particles, and the dispersion of particles as the reason for enhanced heat transport. The reasons proposed by Keblinski et al. [12] include Brownian motion of the particles, molecular-level layering of the liquid at the liquid/particle interface, the nature of heat transport in the nanoparticles, and the effects of nanoparticle clustering. They reported that the key factors are ballistic rather than diffusive nature of heat transport in the nanoparticles, combined with clustering effects that provide paths for rapid heat transport. Buongiorno [13] considered seven possible fluid-particle interaction effects in nanofluid convection (diffusion, inertia, thermophoresis, diffusionphoresis, Magnus effect, fluid drainage, and gravity). He concluded that
Brownian diffusion and thermophoresis play an important role in laminar flow and turbulent viscous layer but are insignificant in the turbulent region, where eddies dominate the motion of nanoparticles.

It is extremely difficult to theoretically estimate the thermophysical properties of nanofluids (since the details of the microstructure and the small scale effects are usually not known accurately). This incomplete understanding also makes the modeling of the nanoparticle flow challenging. Two modeling approaches are summarized next.

1.3. Modeling Nanofluids. A first potential approach to modeling nanofluids uses discrete phase modeling (DPM) and is referred to as the Euler-Lagrangian method. The fluid is treated as a continuous media, and the flow field is solved based on Navier-Stokes equations. The nanoparticles are individually tracked in a Lagrangian reference frame. The motion of each nanoparticle is determined by trying to take into account all local forces on the particle (gravity, thermophoretic, Saffman lift, drag, Brownian, Soret and Dufour, etc.). The nanoparticles can exchange momentum, mass, and energy with the Euler frame fluid phase, and vice versa (if two-way coupling is specified). The DPM approach can be computationally very time consuming, especially if there are a large number of particles. Therefore, the current work uses another modeling approach (called the single-phase approach) that implements experimental data to find empirical thermophysical property correlations (usually polynomials) that best fit the data. The particles and the base fluid mixture are treated as a single fluid with enhanced thermophysical properties, where the enhanced thermophysical properties are evaluated using experimental correlations rather than simple binary mixture rules. However, experimental data in the current literature is scarce, and reliable empirical correlations are only available for thermal conductivity and viscosity of nanofluids. Several researchers [14-16] have compared the accuracy of the two modeling approaches.

\section{Modeling}

2.1. Model Geometry and Problem Description. An integrated circuit (IC) heat sink is shown in Figure 1. The electronic chip has a length $L$ and width $W$ of $10 \mathrm{~mm}$ and a thickness $H$ of $0.5 \mathrm{~mm}$. Nanofluid coolant flows through parallel circular passages with diameter $D$ of $0.1 \mathrm{~mm}$. A constant axial inlet velocity $V_{0}$ and a constant temperature $T_{0}$ of $300 \mathrm{~K}$ are applied at the inlet of the circular channel. No-slip flow condition and a constant heat flux are imposed on the channel wall. A constant mass flow rate and incompressible flow are assumed. A uniform volumetric heat generation rate of $500 \mathrm{~W}$ is assumed inside the chip. Rahman et al. [17] recently presented heat transfer analysis of a magnetic microcooler for NASA applications, where circular microchannels are embedded in a rectangular solid substrate with volumetric heat generation (due to an imposed magnetic field). Due to the symmetry of the problem, only a unit cell consisting of 


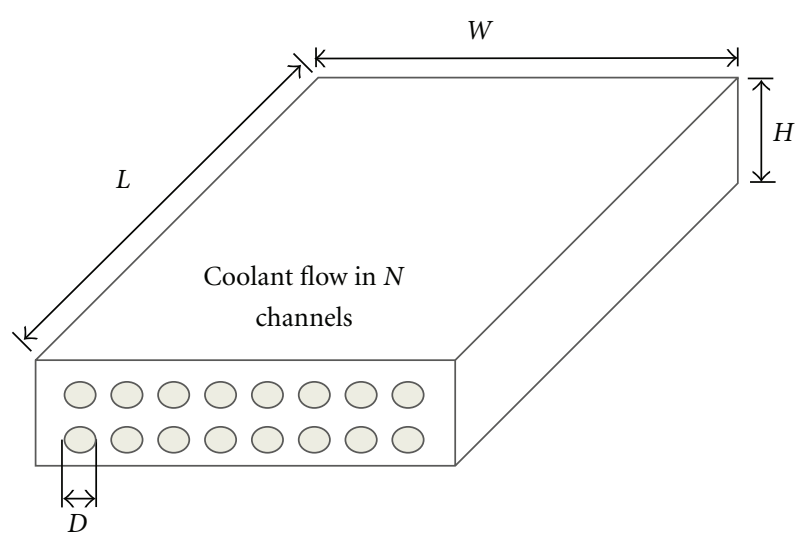

FIgURE 1: The IC heat sink.

a single channel needs to be considered as the computational domain.

In cases where the heat generation in the chip is nonuniform (such as when the heat generation is at the bottom surface of the chip), the channel walls will be subjected to a nonuniform circumferential and axial heat flux. For such cases, evaluating the heat transfer capabilities and optimization of the heat sink will require the use of a 3D finite element or finite volume software package. Since 3D optimization studies are computationally expensive and time consuming, the current model can be used to obtain an approximate solution (initial guess) for further detailed evaluations.

2.2. Thermophysical Properties. The thermophysical properties used in this study are based on the correlations from the literature described later. In the absence of available data in the literature, the effective density $(\rho)$ and specific heat $(c)$ of the nanofluid (nf) are taken as the average of fluid and solid particle densities (based on the volume fraction $\phi$ of the particles in the suspension). Consider

$$
\begin{gathered}
\rho_{\mathrm{nf}}=(1-\phi) \rho_{\mathrm{bf}}+\phi \rho_{p}, \\
c_{\mathrm{nf}}=(1-\phi) c_{\mathrm{bf}}+\phi c_{p} .
\end{gathered}
$$

The effective thermal conductivity is calculated using the model proposed by Chon et al. [18] as follows:

$$
\frac{k_{\mathrm{nf}}}{k_{\mathrm{bf}}}=1+64.7 \phi^{0.7460}\left(\frac{d_{\mathrm{bf}}}{d_{p}}\right)^{0.3690}\left(\frac{k_{p}}{k_{\mathrm{bf}}}\right)^{0.7476} \operatorname{Pr}^{0.9955} R_{p}^{1.2321} .
$$

The Prandtl number Pr and the parameter $R_{p}$ in (3) are defined as

$$
\begin{gathered}
\operatorname{Pr}=\frac{\mu_{\mathrm{bf}}}{\rho_{\mathrm{bf}} \alpha_{\mathrm{bf}}}, \\
R_{p}=\frac{\rho_{\mathrm{bf}} B T}{3 \pi \mu_{\mathrm{bf}}^{2} l_{\mathrm{bf}}},
\end{gathered}
$$

where the subscript bf denotes a property of base fluid (water), $B$ is the Boltzmann constant $\left(1.3807 \times 10^{-23} \mathrm{~J} / \mathrm{K}\right)$,
TABLE 1: Thermophysical properties used in the model [4].

\begin{tabular}{lcc}
\hline & Water & Alumina \\
\hline Density $\left(\mathrm{kg} / \mathrm{m}^{3}\right)$ & 996.54 & 3989.22 \\
Specific heat $(\mathrm{J} / \mathrm{kg} \cdot \mathrm{K})$ & 4177.78 & 778.92 \\
Thermal conductivity $(\mathrm{W} / \mathrm{m} \cdot \mathrm{K})$ & 0.61 & 34.63 \\
Viscosity $(\mathrm{kg} / \mathrm{m} \cdot \mathrm{s})$ & 0.000866 & - \\
\hline
\end{tabular}

and $l_{\mathrm{bf}}$ is the mean free path of base fluid molecules $(0.17 \mathrm{~nm}$ for water molecules).

Maiga et al. [19] proposed a model for viscosity of dilute fluids with spherical nanoparticles, given by

$$
\mu_{\mathrm{nf}}=\mu_{\mathrm{bf}}\left(1+7.3 \phi+123 \phi^{2}\right) .
$$

The properties of water and alumina (evaluated at $300 \mathrm{~K}$ ) used in (1)-(6) are taken from Touloukian [4] and summarized in Table 1.

2.3. Correlations for Modeling Heat Transfer and Pumping Power. Churchill and Ozoe [20] proposed the following correlation for local Nusselt number in a circular channel (assuming hydrodynamically and thermally developing flow conditions):

$$
\begin{gathered}
\frac{\mathrm{Nu}_{x}}{4.364\left[1+(\mathrm{Gz} / 29.6)^{2}\right]^{1 / 6}} \\
=\left\{1+\frac{\mathrm{Gz} / 19.04}{\left[1+(\mathrm{Pr} / 0.0207)^{2 / 3}\left(1+(\mathrm{Gz} / 29.6)^{2}\right)^{1 / 3}\right]^{2 / 3}}\right\}^{1 / 3} .
\end{gathered}
$$

Here, $\mathrm{Gz}$ is the Graetz number given as

$$
\mathrm{Gz}=\frac{\pi D \mathrm{Re}_{D} \operatorname{Pr}}{4 x} .
$$

The Reynolds number is

$$
\operatorname{Re}_{D}=\frac{\rho V_{m} D}{\mu} .
$$

The Prandtl number Pr was defined in (4) earlier. Equation (7) can be used for estimating the local Nusselt number at any given position along the length of the channel, which can then be used to calculate the local heat transfer coefficient as

$$
h_{x}=\frac{k_{\mathrm{nf}} \mathrm{Nu}_{x}}{D} .
$$

The average heat transfer coefficient $h_{\mathrm{av}}$ is obtained by integrating the local heat transfer coefficient (see (10)) over the length $L$ of the channel as follows:

$$
h_{\mathrm{av}}=\frac{1}{L} \int_{0}^{L} h_{x} d x .
$$

Equation (11) is proposed to calculate the average heat transfer coefficient since the typical microchannel passage 
length $L$ in electronics chips is much shorter than the entry length needed to achieve a fully developed flow. Using existing correlations from the literature for average heat transfer coefficient in fully developed flow will yield significantly lower values. The thermal resistance $\theta$ of a heat sink having $N$ channels is the sum of its average convective and volumetric heating resistances, given as

$$
\theta=\frac{1}{N \pi D L h_{\mathrm{av}}}+\frac{1}{\rho_{\mathrm{nf}} c_{\mathrm{nf}}\left(N V_{m} \pi D^{2} / 4\right)} .
$$

The quantity in parenthesis is the volumetric flow rate through the heat sink.

After obtaining the thermal resistance, we also need to evaluate the pumping power needed to move the coolant through the channels. By considering the force balance between the pressure that drives the flow and the opposing friction force due to wall shear stress, we can write an expression for pressure drop $d p$ over a segment $d x$ of a single channel as

$$
d p=\frac{2 \times \operatorname{Po} \times \mu \times \mathrm{V}_{m} \times d x}{D^{2}},
$$

where Po is called the Poiseuille number, $V_{m}$ is the mean velocity, and $\mu$ is the dynamic viscosity of the coolant. The Poiseuille number in developing flow varies along the length of the channel and is given as [21]

$$
\begin{gathered}
\text { Po }=\frac{3.44}{\sqrt{x^{+}}+\frac{16+1.25 /\left(4 x^{+}\right)-3.44 / \sqrt{x^{+}}}{1+\left(2.12 \times 10^{-4}\right) /\left(x^{+}\right)^{2}},} \\
x^{+}=\frac{x}{\operatorname{Re}_{D} D} .
\end{gathered}
$$

The total pressure drop $\Delta p$ over the entire length of a single channel is obtained by substituting (14) into (13), and then integrating over the length $L$ of the channel. The pumping power required to drive the fluid through the $N$ channels of the heat sink is the product of pressure drop and flow rate as follows:

$$
\bar{P}=\Delta p \times N \times \pi \times\left(\frac{D^{2}}{4}\right) \times V_{m} .
$$

In the present study, the thermal resistance given by (12) is minimized using a constant specified value of available pumping power (see (16)) as the constraint. The minimization is performed using a genetic algorithm (GA) as described later.

\section{Model Validation}

In order to validate our model, the heat transfer coefficient predictions of the proposed model are compared with the experimental data from the literature. Anoop et al. [22] experimentally investigated convective heat transfer for developing laminar flow using alumina particles with size of $45 \mathrm{~nm}$ and $150 \mathrm{~nm}$. A copper tube of $1.2 \mathrm{~m}$ length and $4.75 \mathrm{~mm}$ inner diameter was uniformly heated with power input of $200 \mathrm{~W}$. The average heat transfer coefficient was

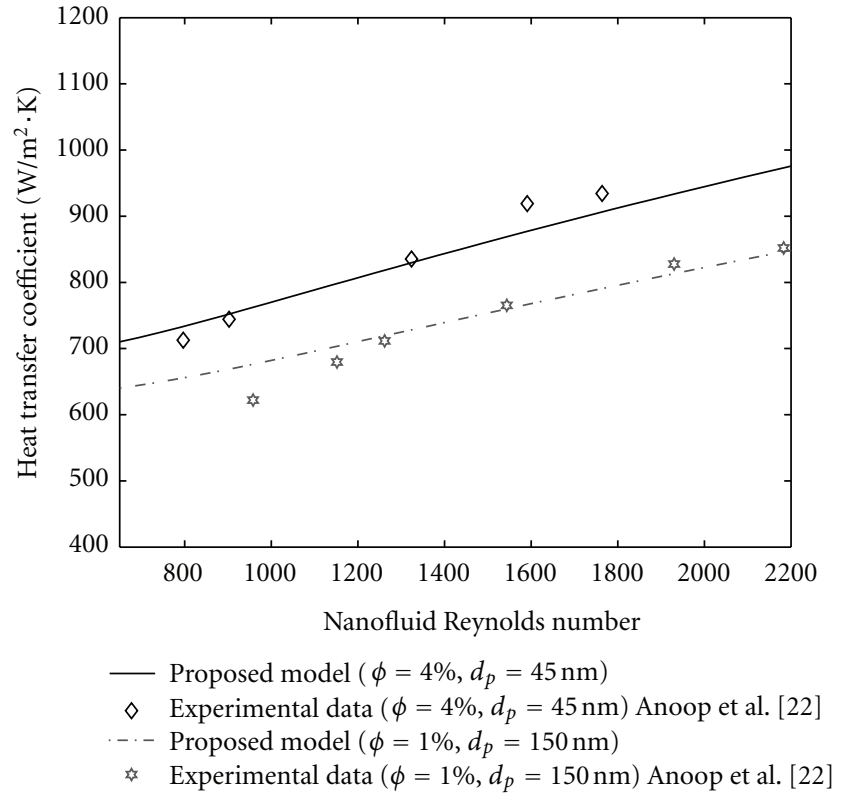

Figure 2: Average heat transfer coefficient over the channel length versus Reynolds numbers.

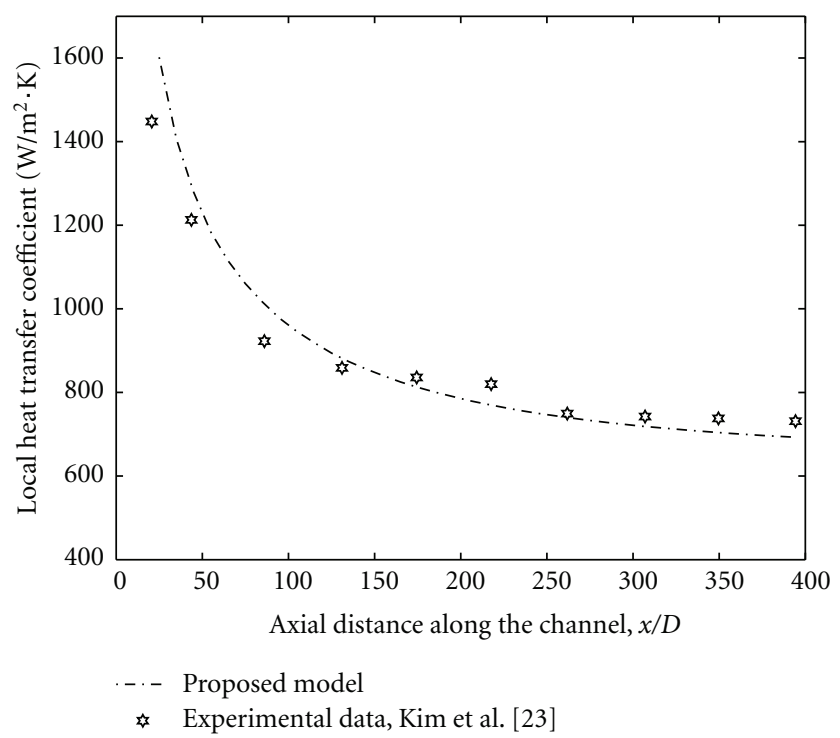

FIGURE 3: Local heat transfer coefficient along the channel versus dimensionless axial distance.

measured as a function of Reynolds number. Kim et al. [23] performed an experimental study to investigate the effects of nanofluids on convective heat transfer in a straight circular tube $(D=4.57 \mathrm{~mm}, L=2 \mathrm{~m})$ subjected to uniform heat flux of $2090 \mathrm{~W} / \mathrm{m}^{2}$ on the tube wall. A 3 percent alumina-water nanofluid at $22^{\circ} \mathrm{C}$ was used as the coolant. The Reynolds number was 1460 . The average size of the alumina nanoparticle was $35 \mathrm{~nm}$. The local heat transfer coefficient was measured at various positions along the length of the tube.

The results of model validation are presented in Figures 2 and 3. Our model overpredicts the experimental value of heat 
transfer coefficient by a relative error of 15 percent near the channel entrance but in general is in good agreement with experimental results.

\section{Optimization Methodology and Procedure}

Different estimation methods were considered; however, due to the flatness of the fitness function, a GA was selected because of its robust nongradient-based optimization approach. More information regarding the principles of GAs can be found in Goldberg [24]. The GA is used to solve for the optimal values of the four unknown parameters that include the channel diameter $D$, number of channels $N$, flow velocity $V_{m}$, and particle volume fraction $\phi$. Since it has been shown previously [25] that smaller particles improve thermal performance without pressure drop penalty, $10 \mathrm{~nm}$ is used as the particle size as no experimental data are available for behavior of particles smaller than this size.

The GA solves for the optimal values of the parameters by maximizing the fitness function. The fitness function is equal to inverse of heat sink thermal resistance (see (12)) when pumping power is within specified limit. A zero value is assigned to the fitness function if the parameter estimates produce pumping power greater than the specified limit.

The GA is programmed in MATLAB scripting language and based on the algorithm by Goldberg [24]. In the implementation of the GA, the potential solution (chromosome) contains the channel diameter $D$, flow velocity $V_{m}$, number of channels $N$, and particle volume fraction $\phi$, as the 4 genes and 10 bits are used to represent the value of each gene in binary format. Therefore, each chromosome has 40 bits. The population size is chosen to be 20 . The initial population pool is generated using a random number generator after which they reproduce for 200 generations. The parameters contained in each chromosome are changed from their binary representation to floating point representation using (for the $i$ th parameter)

$$
P_{i}=a+\frac{b-a}{2^{\text {nb }}-1}(m)
$$

where $P_{i}$ is the decimal value of $i$ th parameter, $a$ and $b$ are the lower and upper limits of the search interval, respectively, $\mathrm{nb}$ is the number of bits used to represent the parameter (10 in this case), and $m$ is the decimal value of the parameter in binary form. The lower limit $a$ and the upper limit $b$ are 50 and $400 \mu \mathrm{m}$ for the channel diameter, 1 and $10 \mathrm{~m} / \mathrm{s}$ for the flow velocity, 1 and 10 percent for the volume fraction, and 1 and $N_{\max }$ for the channel count. The maximum channel count is given by

$$
N_{\max }=\mathrm{nl} \frac{W-t_{\min }}{\left(D+t_{\min }\right)}
$$

where $W$ is the width of the heat sink, and $t_{\min }$ is the minimum distance between channels which is set equal to $50 \mu \mathrm{m}$ in this study. Here, $\mathrm{nl}$ is the number of channel layers that can be accommodated by height $H$ of the heat sink, calculated as

$$
\mathrm{nl}=\frac{H-t_{\min }}{\left(D+t_{\min }\right)}
$$

and rounded down to the nearest whole number.

The inverse of thermal resistance (see (12)) is used as the fitness of each chromosome. A chromosome of higher fitness is more likely to be selected to reproduce and contribute its genetic material to the next generation. A probability of mutation (random changing of a chromosome) of 0.20 and a probability of crossover (formation of children) equal to 0.90 are used to determine how members of the population will reproduce to bring forth the next generation. Several cases (with different limits on available pumping power) were simulated to predict the optimal heat sink parameters. For any given value of available pumping power, optimization was done by considering both nanofluid and base fluid (water) as the coolant in the channels. For cases with only base fluid (water) as the coolants, the volume fraction is set equal to zero which forces the proposed model to adopt water properties instead of nanofluid effective properties.

\section{Results and Discussions}

For each level of maximum pumping power considered in this study, the minimized thermal resistance of the nanofluid heat sink and the corresponding values of the parameters are presented in Table 2. The results of minimization using only the base fluid as the coolant are presented in Table 3. A comparison between the thermal resistances of base fluid and the nanofluid is shown in Figure 4. The results show only a small decrease $(0.003 \mathrm{C} / \mathrm{W}$ at $0.1,0.5$, and $0.9 \mathrm{~W}$ of available pumping power) in thermal resistance through the addition of particles. The benefit decreases further at higher levels of pumping power $(0.002 \mathrm{C} / \mathrm{W}$ at $1.5,2.5$, and $3.5 \mathrm{~W})$.

The solutions at relatively low values of pumping power $(0.1,0.5$, and $0.9 \mathrm{~W})$ converge towards an optimal diameter of $175 \mu \mathrm{m}$, which in this specific study is the minimum diameter that would allow two stacked layers with a total of 88 channels (see (18) and (19)). The optimal solutions for relatively high values of pumping power $(1.5,2.5$, and $3.5 \mathrm{~W}$ ) converge towards an optimal diameter of $100 \mu \mathrm{m}$ and 198 channels. Once again, for the specific values of heat sink dimensions and minimum channel spacing used in this study, $100 \mu \mathrm{m}$ is the minimum diameter that would allow three stacked channel layers with 198 channels. The optimal diameter and number of channels are the same for both water and nanofluid coolant cases. For a given optimal geometry (diameter and number of channels), higher available pumping power leads to both a higher velocity and a higher volume fraction.

In general, the thermal resistance can be lowered with more particles (higher volume fraction) added to the flow and also with higher flow rate or velocity. Both of these will impose some additional pumping power penalty. Under the constraint of a given pumping power, the benefit of nanoparticle addition must be evaluated by independently minimizing the thermal resistance of the base fluid and 
TABLE 2: Thermal resistance for microchannel heat sink with nanofluid coolant.

\begin{tabular}{lcccccc}
\hline $\begin{array}{l}\text { Power } \\
(\mathrm{W})\end{array}$ & $\begin{array}{c}\text { Diameter } \\
(\mu \mathrm{m})\end{array}$ & $\begin{array}{c}\text { Velocity } \\
(\mathrm{m} / \mathrm{s})\end{array}$ & Channel count & $\begin{array}{c}\text { Volume fraction } \\
(\%)\end{array}$ & $\begin{array}{c}\text { Reynolds number } \\
\begin{array}{c}\text { Resistance } \\
(\mathrm{C} / \mathrm{W})\end{array}\end{array}$ \\
\hline 0.1 & 175 & 1.73 & 88 & 2.38 & 303 & 0.136 \\
0.5 & 175 & 3.35 & 88 & 3.49 & 538 & 0.088 \\
0.9 & 175 & 4.22 & 88 & 4.22 & 634 & 0.076 \\
1.5 & 100 & 4.58 & 198 & 2.18 & 466 & 0.066 \\
2.5 & 100 & 5.75 & 198 & 2.19 & 585 & 0.057 \\
3.5 & 100 & 6.64 & 198 & 2.34 & 668 & 0.052 \\
\hline
\end{tabular}

TABLE 3: Thermal resistance for microchannel heat sink with base fluid coolant.

\begin{tabular}{lccccc}
\hline $\begin{array}{l}\text { Pumping } \\
\text { power }(\mathrm{W})\end{array}$ & $\begin{array}{c}\text { Diameter } \\
(\mu \mathrm{m})\end{array}$ & $\begin{array}{c}\text { Velocity } \\
(\mathrm{m} / \mathrm{s})\end{array}$ & $\begin{array}{c}\text { Channel } \\
\text { count }\end{array}$ & $\begin{array}{c}\text { Reynolds } \\
\text { number }\end{array}$ & $\begin{array}{c}\text { Resistance } \\
(\mathrm{C} / \mathrm{W})\end{array}$ \\
\hline 0.1 & 175 & 1.87 & 88 & 381 & 0.139 \\
0.5 & 175 & 3.76 & 88 & 766 & 0.091 \\
0.9 & 175 & 4.83 & 88 & 983 & 0.079 \\
1.5 & 100 & 4.93 & 198 & 574 & 0.068 \\
2.5 & 100 & 6.18 & 198 & 719 & 0.059 \\
3.5 & 100 & 7.15 & 198 & 833 & 0.054 \\
\hline
\end{tabular}

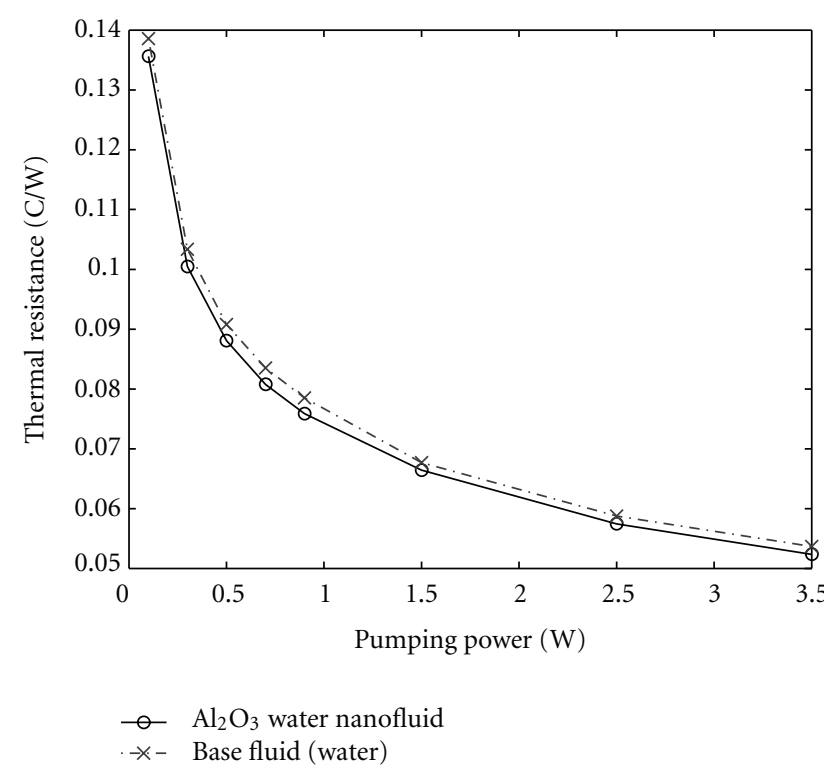

Figure 4: Minimized thermal resistance versus pumping power for heat sink using base fluid and alumina-water nanofluid coolant.

nanofluid heat sink. The minimization is achieved through some optimal combination of velocity and volume fraction for the case of nanofluid heat sink (Table 2) and through an optimal velocity in case of base fluid heat sink (Table 3). For any given power level, a higher optimal velocity in the base fluid heat sink can largely compensate for the lack of nanoparticle addition. As a result, only a small benefit is reported in the study, as opposed to other studies in the literature where pumping power considerations are often neglected, and the heat transfer improvement of nanofluids over base fluid is reported at a specified Reynolds number or flow rate. Not taking the pumping power into consideration would have led to the absurd conclusion that the performance would improve indefinitely with higher volume fraction.

\section{Conclusions}

A semianalytical model is presented to evaluate the heat transfer and flow characteristics of a nanofluid heat sink with developing flow laminar forced convection. The model is used to predict the thermal resistance and pumping power as a function of four design variables that include the channel diameter, the flow velocity, number of channels, and the particle volume fraction. The robust nongradient-based approach of a genetic algorithm was successfully applied to find optimal design with minimum thermal resistance as the objective and fixed specified value of pumping power as the constraint. The study revealed that for a given pumping power, only a small benefit is achieved through nanofluid coolants when the comparison is made by independently optimizing the heat sink, first with nanofluid and then with base fluid. This is because the nanoparticles increase the pumping power which can alternately be diverted towards an increased velocity in a pure fluid heat sink. The benefit of adding nanoparticles is further decreased as the available pumping power is increased. The methodology and results presented here would be useful for the understanding and optimal design of microchannel heat sinks with nanofluid flow. The current model and estimation methodology are flexible enough to be extended to the case of nonuniform heat flux on the channel walls in future studies. For more accurate results that take into account the effect of axial conduction along the channels, three-dimensional finite element model can be created with a single-phase coolant in channels that have effective nanofluid properties.

\section{Nomenclature}

a: Lower limit value for the search interval of a design parameter

$b$ : Upper limit value for the search interval of a design parameter

c: Specific heat

$d x$ : Differential length along the channel wall (m) 
$D: \quad$ Channel diameter $(\mathrm{m})$

Gz: Graetz number

$h$ : Heat transfer coefficient $\left(\mathrm{W} / \mathrm{m}^{2} \cdot \mathrm{K}\right)$

$H$ : Height (meter)

$k$ : Thermal conductivity $(\mathrm{W} / \mathrm{m} \cdot \mathrm{K})$

$l, L$ : Length (m)

$m$ : The equivalent decimal value of a design parameter in binary form

nb: The number of bits used to represent a design parameter in binary form

nl: The number of channel layers accommodated by heat sink cross-section

$N$ : The total number of channels in heat sink

$\mathrm{Nu}$ : Nusselt number

$p: \quad$ Pressure $\left(\mathrm{N} / \mathrm{m}^{2}\right)$

$\bar{P}: \quad$ Pumping power $(\mathrm{W})$

Po: Poiseuille number

Pr: Prandtl number

$q$ : Heat transfer (W)

$R$ : Thermal resistance

Re: Reynolds number

T: Temperature, ${ }^{\circ} \mathrm{C}$

$V$ : Velocity $(\mathrm{m} / \mathrm{s})$

$W$ : Width (m)

$x$ : Axial distance (m).

\section{Greek Symbols}

$\alpha$ : Thermal diffusivity $\left(\mathrm{m}^{2} / \mathrm{s}\right)$

$\rho:$ Density $\left(\mathrm{kg} / \mathrm{m}^{3}\right)$

$\nabla:$ Gradient operator

$\mu$ : Viscosity ( $\mathrm{kg} / \mathrm{m} . \mathrm{s})$

$\eta$ : Model output

$\phi$ : Percent volume fraction

$v$ : Kinematic viscosity $\left(\mathrm{m}^{2} / \mathrm{s}\right)$.

\section{Subscripts}

0 : Reference or inlet value

av: Average

bf: Base fluid (water)

$D$ : Property evaluated based on diameter or hydraulic diameter

$i$ : ith parameter or variable

nf: Nanofluid $\left(\mathrm{Al}_{2} \mathrm{O}_{3}\right.$-water $)$

$m:$ Mean/average

$p$ : Nanoparticle.

\section{Superscripts}

+: Dimensionless quantity.

\section{References}

[1] D. B. Tuckerman and R. F. W. Pease, "High performance heat sinking for VLSI," IEEE Electronic Device Letters, vol. 2, no. 5, pp. 126-129, 1981.

[2] S. S. Mehendale, A. M. Jacobi, and R. K. Shah, "Fluid flow and heat transfer at micro- and meso-scales with application to heat exchanger design," Applied Mechanics Reviews, vol. 53, no. 7, pp. 175-193, 2000.

[3] S. G. Kandlikar and W. J. Grande, "Evolution of microchannel flow passages-thermohydraulic performance and fabrication technology," Heat Transfer Engineering, vol. 24, no. 1, pp. 317, 2003.

[4] Y. S. Touloukian, Thermophysical Properties of Matter: The TPRC Data Series; A Comprehensive Compilation of Data, IFI/Plenum, New York, NY, USA, 1970.

[5] X. Q. Wang and A. S. Mujumdar, "Heat transfer characteristics of nanofluids: a review," International Journal of Thermal Sciences, vol. 46, no. 1, pp. 1-19, 2007.

[6] C. Okhio, D. Hodges, and J. Black, "Review of literature on nanofluid flow and heat transfer properties, cyber journals: multidisciplinary journals in science and technology," Journal of Selected Areas in Nanotechnology, vol. 12, pp. 1-8, 2010.

[7] S. Kakac and A. Pramuanjaroenkij, "Review of convective heat transfer enhancement with nanofluids," International Journal of Heat and Mass Transfer, vol. 52, no. 13-14, pp. 3187-3196, 2009.

[8] G. Huminic and A. Huminic, "Application of nanofluids in heat exchangers: a review," Renewable and Sustainable Energy Reviews, vol. 16, no. 8, pp. 5625-5638, 2012.

[9] S. K. Das, S. U. Choi, W. Yu, and T. Pradeep, Nanofluids: Science and Technology, John Wiley \& Sons, Hoboken, NJ, USA, 2008.

[10] X. Wang, X. Xu, and S. U. S. Choi, "Thermal conductivity of nanoparticle-fluid mixture," Journal of Thermophysics and Heat Transfer, vol. 13, no. 4, pp. 474-480, 1999.

[11] Y. Xuan and Q. Li, "Investigation on convective heat transfer and flow features of nanofluids," Journal of Heat Transfer, vol. 125, no. 1, pp. 151-155, 2003.

[12] P. Keblinski, S. R. Phillpot, S. U. S. Choi, and J. A. Eastman, "Mechanisms of heat flow in suspensions of nano-sized particles (nanofluids)," International Journal of Heat and Mass Transfer, vol. 45, no. 4, pp. 855-863, 2001.

[13] J. Buongiorno, "Convective transport in nanofluids," Journal of Heat Transfer, vol. 128, no. 3, pp. 240-250, 2006.

[14] R. Lotfi, Y. Saboohi, and A. M. Rashidi, "Numerical study of forced convective heat transfer of Nanofluids: Comparison of different approaches," International Communications in Heat and Mass Transfer, vol. 37, no. 1, pp. 74-78, 2010.

[15] V. Bianco, F. Chiacchio, O. Manca, and S. Nardini, "Numerical investigation of nanofluids forced convection in circular tubes," Applied Thermal Engineering, vol. 29, no. 17-18, pp. 3632-3642, 2009.

[16] V. Bianco, O. Manca, and S. Nardini, "Numerical investigation on nanofluids turbulent convection heat transfer inside a circular tube," International Journal of Thermal Sciences, vol. 50, no. 3, pp. 341-349, 2011.

[17] M. M. Rahman, A. A. Gari, and S. Shevade, "Heat transfer in circular microchannels during volumetric heating with magnetic field," Heat and Mass Transfer, vol. 44, no. 4, pp. 463472, 2008.

[18] C. H. Chon, K. D. Kihm, S. P. Lee, and S. U. S. Choi, "Empirical correlation finding the role of temperature and particle size for nanofluid $\left(\mathrm{Al}_{2} \mathrm{O}_{3}\right)$ thermal conductivity enhancement," Applied Physics Letters, vol. 87, no. 15, Article ID 153107, pp. $1-3,2005$.

[19] S. E. B. Maïga, S. J. Palm, C. T. Nguyen, G. Roy, and N. Galanis, "Heat transfer enhancement by using nanofluids in forced convection flows," International Journal of Heat and Fluid Flow, vol. 26, no. 4, pp. 530-546, 2005. 
[20] S. W. Churchill and H. Ozoe, "Correlations for laminar forced convection with uniform heating in flow over a plate and in developing and fully developed flow in a tube," Transactions of the ASME Journal of Heat Transfer, vol. 95, no. 1, pp. 78-84, 1973.

[21] R. K. Shah, "Correlation for laminar hydrodynamic entry length solutions for circular and noncircular ducts," Transactions of the ASME Journal of Fluids Engineering, vol. 100, no. 2, pp. 177-179, 1978.

[22] K. B. Anoop, T. Sundararajan, and S. K. Das, "Effect of particle size on the convective heat transfer in nanofluid in the developing region," International Journal of Heat and Mass Transfer, vol. 52, no. 9-10, pp. 2189-2195, 2009.

[23] D. Kim, Y. Kwon, Y. Cho et al., "Convective heat transfer characteristics of nanofluids under laminar and turbulent flow conditions," Current Applied Physics, vol. 9, no. 2, pp. e119e123, 2009.

[24] D. E. Goldberg, Genetic Algorithms in Search, Optimization and Machine Learning, Addison-Wesley, Reading, Mass, USA, 1989.

[25] M. Mital, "Analytical analysis of heat transfer and pumping power of laminar nanofluid developing flow in microchannels," Applied Thermal Engineering, vol. 50, no. 1, pp. 429-436, 2012. 

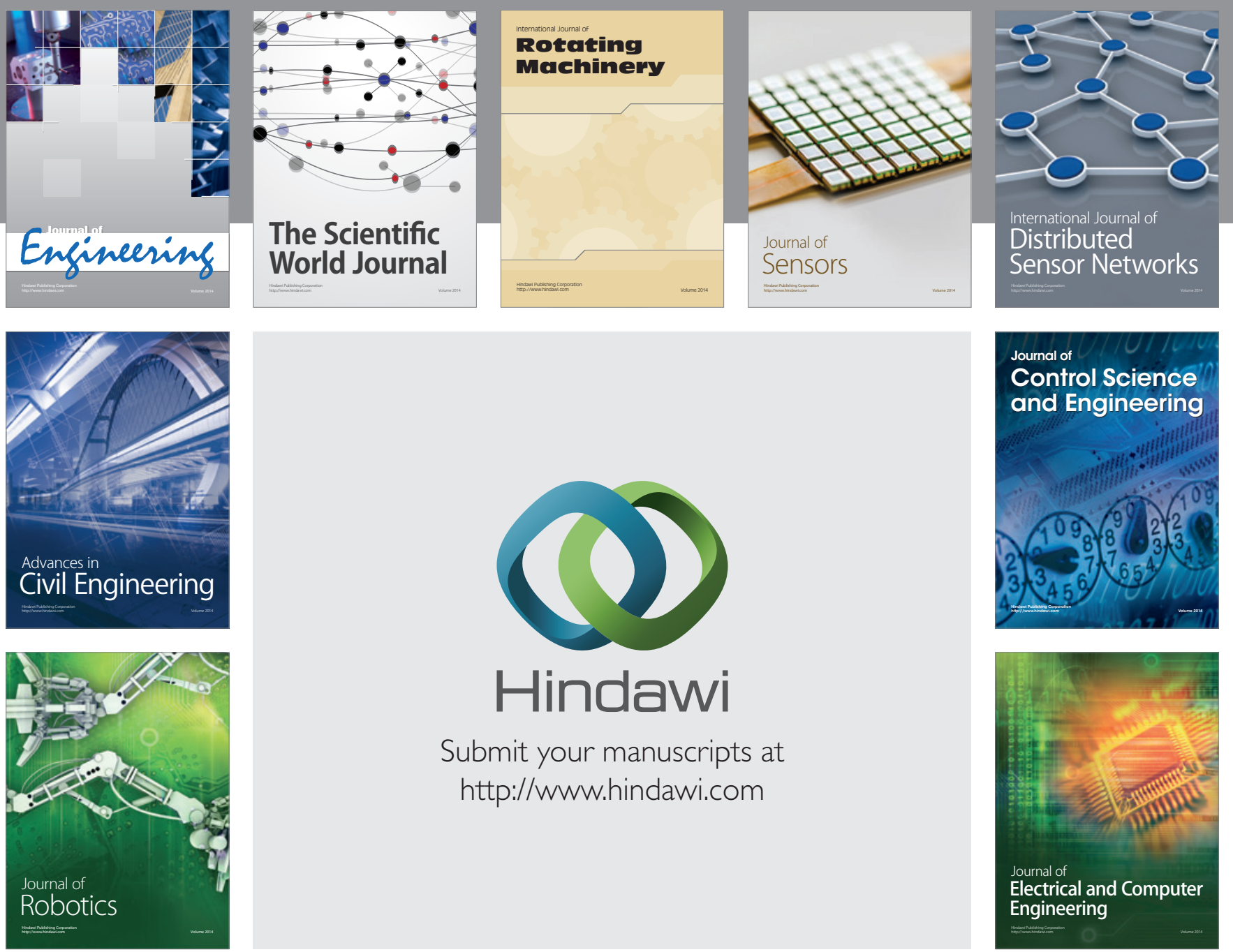

Submit your manuscripts at

http://www.hindawi.com
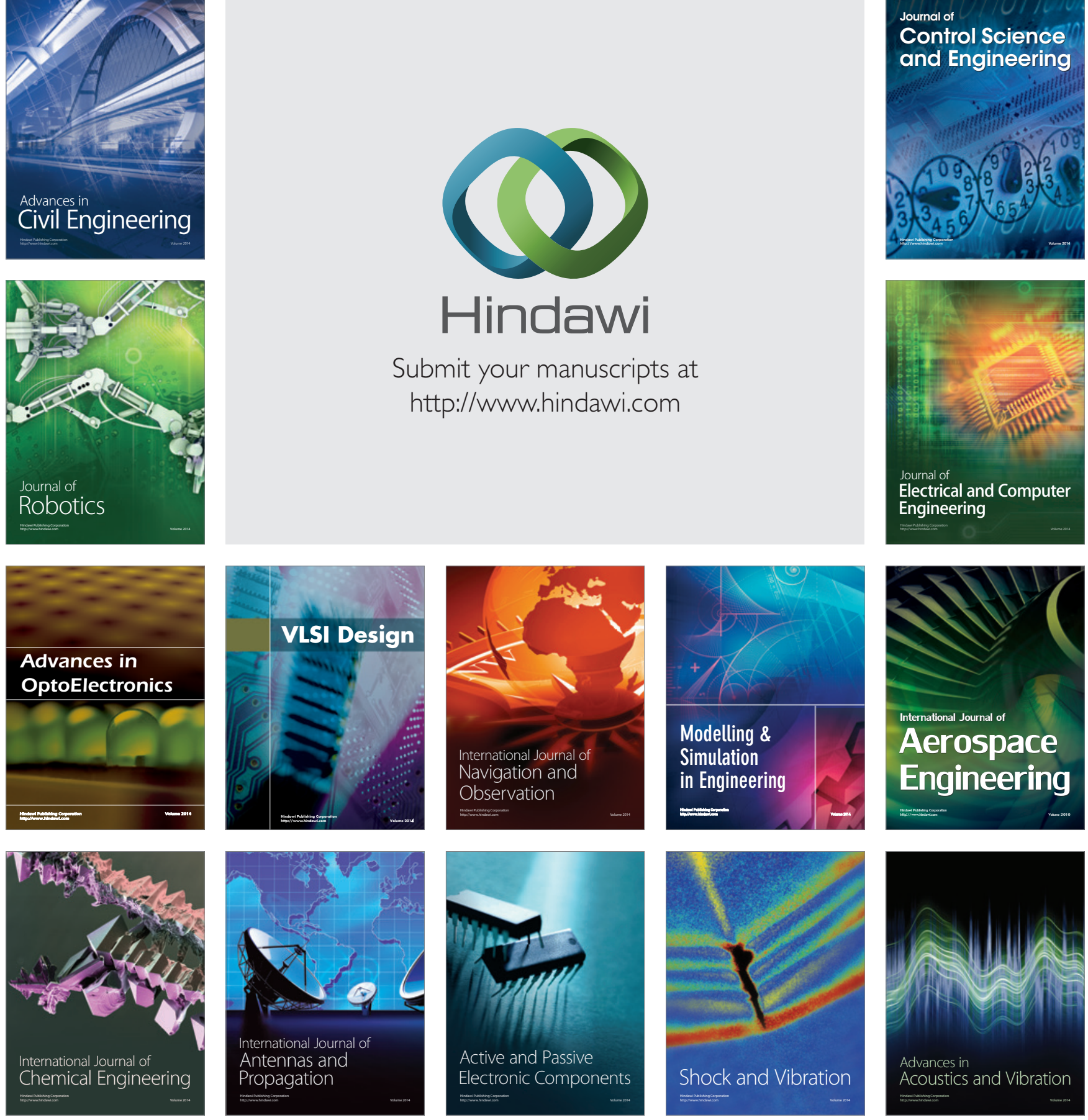